\title{
Is Vegetarianism a Solution for Obesity and NCDs? A Review
}

\author{
Ana María Zelaya, Elisa M. Sinibaldi \\ Universidad Francisco Marroquin, Guatemala City, Guatemala \\ Email: anazelaya@ufm.edu, emsinibaldi@ufm.edu
}

How to cite this paper: Zelaya, A.M. and Sinibaldi, E.M. (2021) Is Vegetarianism a Solution for Obesity and NCDs? A Review. Food and Nutrition Sciences, 12, 249-261. https://doi.org/10.4236/fns.2021.123020

Received: February 11, 2021

Accepted: March 13, 2021

Published: March 16, 2021

Copyright $\odot 2021$ by author(s) and Scientific Research Publishing Inc. This work is licensed under the Creative Commons Attribution International License (CC BY 4.0).

http://creativecommons.org/licenses/by/4.0/

(c) (i) Open Access

\begin{abstract}
Purpose of Review: Obesity is defined as an abnormal fat accumulation associated with disease development risk. The prevalence of obesity and non-communicable diseases (NCDs) continues to increase at a concerning pace. The modern lifestyle requires people to rely on processed foods because of their efficiency and low-cost, which are associated with obesity and NCDs. Vegetarian diet refers to the exclusion of meat, fish, seafood and can also exclude animal products such as dairy and eggs. Therefore, the purpose of this review is to explore vegetarianism as a potential solution for obesity and the development of non-communicable diseases. Recent Findings. Meat intake is also related to unhealthy food groups consumption, contributing to overall poor diet quality. In contrast, vegetarian diets are associated with higher satiety, resulting in less food intake, favoring weight reduction. Lowering the prevalence of NCDs should be a priority, and nutritional interventions are pivotal to accomplish this goal. Summary. Vegetarian diets are associated with weight loss due to: fiber content, lower caloric density, microbiota regulation, and the release of gastrointestinal appetite-regulating hormones. Plant-based eating patterns have demonstrated an overall healthier diet and can be a potential solution for obesity and NCDs' development.
\end{abstract}

\section{Keywords}

Vegetarianism, Plant-Based, Obesity, Weight Loss, Non-Communicable Diseases

\section{Introduction}

There are currently many threats to global health, and it is well known that obesity is one of them. Obesity is the sixth risk factor for death worldwide, and it concerns how it has tripled in the last few decades [1] [2]. Obesity is defined as an abnormal fat accumulation associated with risk of disease development. Ob- 
esity is when a person has a body mass index (BMI) above $30 \mathrm{~kg} / \mathrm{m}^{2}$ and overweight when BMI is above $25 \mathrm{~kg} / \mathrm{m}^{2}$ [2]. According to the World Health Organization (WHO), in 2016, 39\% of adults suffered from being overweight and 13\% from obesity [2]. There is a common misconception of the word malnutrition because it is immediately assumed that this term refers to undernutrition. However, malnutrition refers to an altered nutritional status, either by deficit or excess [3].

Modern lifestyle requires people to rely on efficient and low-cost food options. The consumption of processed foods and ready to eat meals has been associated with the development of obesity and non-communicable diseases (NCDs) [3]. Non-communicable diseases are chronic, non-infectious, and non-transmissible medical conditions that increase cardiovascular disease and mortality risk [4]. Recent studies have also shown that there might be an association between the consumption of processed food during the first 1000 days of life and stunting. Although more evidence is needed to confirm this relationship, these findings would help to further understand the increasing rates of the double burden of malnutrition [3] [5]. As Wendell Berry said, "People are fed by the food industry, which pays no attention to health and is treated by the health industry, which pays no attention to food."

To date, the restless search for an ideal diet to fight obesity is nowhere near done. It is known that some diets favor weight loss and decrease the incidence of NCDs. Vegetarian diets are becoming popular among researchers due to their emerging evidence regarding health benefits [6]. A vegetarian diet refers to the exclusion of meat, fish, seafood and can also exclude animal products such as dairy and eggs [7]. Therefore, the purpose of this review is to explore vegetarianism as a potential solution for obesity and the development of non-communicable diseases.

\section{Relationship between Omnivore Diets and Weight Gain}

Diet culture has distorted food choices and eating behavior when trying to achieve weight loss. A popular trend is the complete avoidance of carbohydrates and starchy vegetables, encouraging high protein (HP) diets. However, the efficiency of HP diets for weight loss is still inconclusive [8]. It is ironic how there is evidence regarding the high intake of red and processed meats and the association with increased morbidity and mortality, and still, these diets are preferred [9].

Meat consumption has been associated with higher morbidity and mortality, but is it really the best way to lose weight? A multicenter, prospective cohort study showed that the consumption of $250 \mathrm{~g}$ of meat per day (approximately 1 steak) would result in a 2 kilogram or higher weight gain in a 5-year period [10]. Also, a multiethnic cohort study found a significant, positive association between red and processed meat intake with BMI in women $(\beta=0.036, \mathrm{p}<0.0001)$ and men $(\beta=0.034, \mathrm{p}=0.0004)$. This same study demonstrated a significant positive association between meat consumption and serum leptin levels [women 
$(\beta=0.167, \mathrm{p}<0.0001)$, men $(\beta=0.180, \mathrm{p}=0.0004)][11]$.

Meat intake is also related to unhealthy food groups consumption, contributing to an overall poor diet quality [9] [12]. Many recent guidelines now recommend that adults restrict red and processed meat to no more than $70 \mathrm{~g}$ per day. This would improve diet quality and health and provide environmental benefits [13].

\section{Vegetarianism as a Strategy for Weight Loss}

Vegetarianism is a dietary profile characterized by the omission of meat, meat products, poultry, and seafood from the diet as shown in Figure 1 [14]. People may adopt this dietary pattern due to religious, ethical, cultural, environmental, or health reasons [6]. Vegetarian diets are usually composed of whole foods with lower calorie density than processed foods. Low-density foods have higher amounts of fiber, which in turn promotes satiety [15].

In 2016, a meta-analysis of randomized controlled trials showed a 2 kilogram weight reduction in those subjects who followed a vegetarian pattern. There are multiple explanations for the effect of vegetarian diets on weight loss, and one of them is fiber intake [16]. Fiber benefits are partly due to viscosity, the degree of resistance to flow, leading to a decreased gastric emptying rate, and modulation of small intestinal transit. Therefore, individuals have increased satiety and less food intake, favoring weight reduction [17].

Calorie restrictions are one of the most common methods for weight reduction. Nonetheless, restricting calories doesn't necessarily improve diet quality or composition. Plant-based diets are known for having a higher Alternate Healthy Eating Index (AHEI), which would benefit overall health rather than only seeking weight reduction [18]. A lifestyle modification 8-week program demonstrated a statistically significant weight loss of $5.7 \%$ of body weight in participants consuming a plant-based diet $(\mathrm{p}<0.0001)$. Participants were allowed to eat ad libitum whole foods, excluding animal-based foods and processed foods. Blood pressure, total and LDL cholesterol also decreased significantly [decrease in blood pressure $(\mathrm{p}=0.0002)$, decrease in total cholesterol $(\mathrm{p}<0.0001)$, decrease in LDL cholesterol $(\mathrm{p}<0.0001)]$ [19].

\section{Adherence to Vegetarian Diets}

It is a common concern that vegetarian or vegan diets are bound to fail due to the idea of them being too restrictive. The New DIETSs study investigated dietary adherence and acceptability of four plant-based diets (vegan, vegetarian, pesco-vegetarian, semi-vegetarian) or an omnivore diet. The study found similar dietary adherence between all five dietary patterns and a greater weight reduction in non-adherent individuals on a meat-free diet compared to non-adherent individuals on an omnivore diet [20].

Dietary adherence is crucial for achieving any health and weight goal and should be considered when tailoring a weight loss plan. Practitioners need to ask themselves how they may optimize patient adherence [21], which might be chal- 
lenging if individuals feel hungry throughout the process. As shown in Figure 2 [22], a vegetarian meal with similar energy and macronutrient content as an omnivore meal can be more voluminous due to the lower calorie density of plant-based foods.

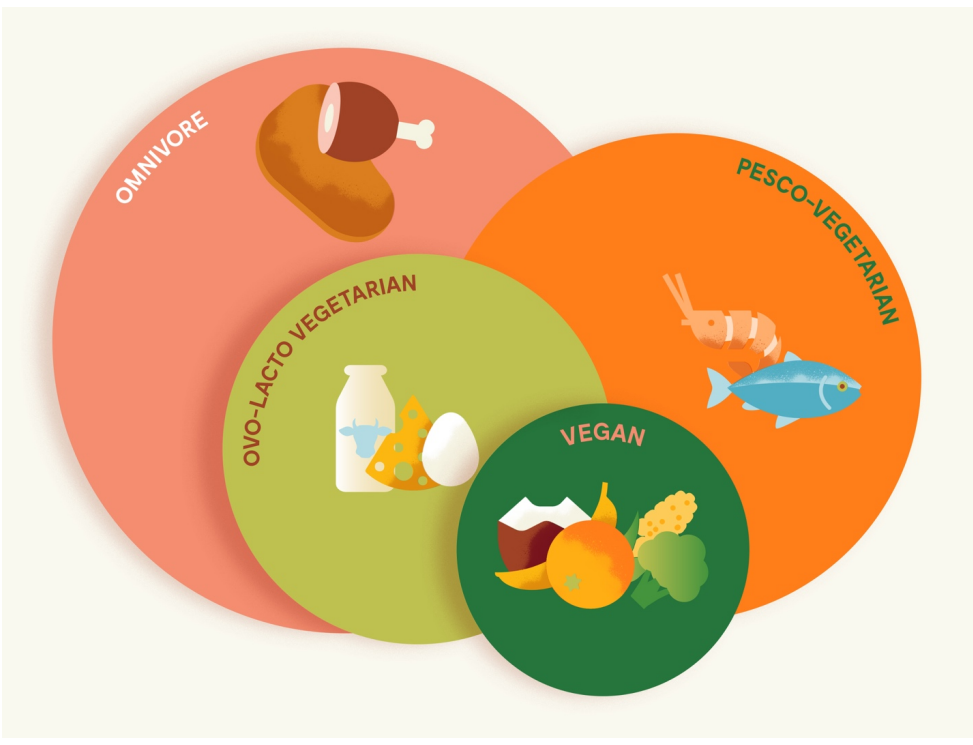

Figure 1. Dietary patterns: from vegan to omnivore. Vegan: excludes all animal products from the diet; Ovo-Lacto-Vegetarian: a dietary pattern that adds dairy and eggs to a vegetarian diet; Pesco-vegetarian: a dietary pattern that adds seafood to a vegetarian diet; Omnivore: includes all food items and animal products.

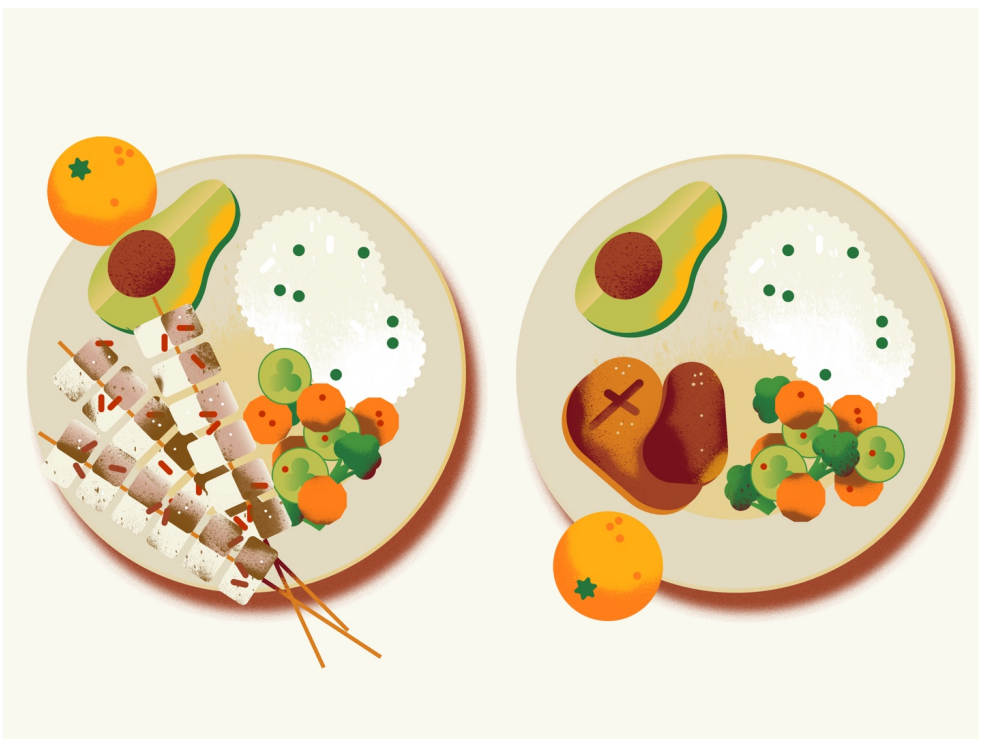

Figure 2. Comparison between an omnivore and vegetarian meal. The vegetarian meal (left) consists of $11 / 4$ cup of tofu skewers, $2 \mathrm{oz}$ of avocado, 1 cup of cooked vegetables, 1 cup of cooked rice, and a piece of fruit. The omnivore meal (right) consists of $3 \mathrm{oz}$ of beef, $2 \mathrm{oz}$ of avocado, 1 cup of cooked vegetables, 1 cup of cooked rice, and a piece of fruit. Both meals provide approximately $600 \mathrm{kcal}, 30 \mathrm{~g}$ protein, $70 \mathrm{~g}$ carbohydrates, and $20 \mathrm{~g}$ fat. The food portions are based on the Choose Your Foods, Food Lists guideline by the American Diabetes Association and Academy of Nutrition and Dietetics. 
Changes in appetite when following a plant-based diet are influenced by the fiber content. Fiber is fermented by the gut microbiota, resulting in the production of short-chain fatty acids (SCFA); thereby, stimulating the release of peptide YY (PYY) and glucagon-like peptide (GLP-1). These promote satiety by suppressing appetite and delaying gastric emptying [15].

Klementova, M., and colleagues evaluated the postprandial metabolism of gastrointestinal hormones and satiety in response to a pork meat burger and tofu burger. 60 men participated in the randomized control study (men with T2DM $=20$, men with obesity $=20$, healthy men $=20$ ). The study evidenced that all groups reported more satiety with the tofu burger compared to the meat burger: participants with T2DM increased satiety by $9 \%(95 \% \mathrm{CI}, \mathrm{p}=0.004)$, subjects with obesity by $18.7 \%$ ( $95 \% \mathrm{CI}, \mathrm{p}<0.001)$, and healthy men by $25 \%$ (95\% CI; $\mathrm{p}<$ 0.001 ). There was also an increase in the postprandial secretion of GLP-1 and PYY. The study concluded that the plant-based meal promoted higher satiety than the processed meat meal [23].

More evidence is required to understand further how plant-based diets promote satiety. However, these findings are suggestive that this dietary pattern induces appetite suppression and promotes satiety by the production of SCFAs, leading to the release of gastrointestinal appetite-regulating hormones.

\section{Do Vegetarian Diets Prevent NCDs?}

The prevalence of a variety of NCDs has drastically increased, and there is a concern over the link between meat intake and the susceptibility of these diseases [9]. New technologies and advances in breeding practices have increased the availability and reduced costs of animal production in the industrialized world. Between 2014 and 2016, the average meat consumption per capita globally was $34.1 \mathrm{~kg} /$ per annum, $60 \%$ from red meat [12]. Lowering the prevalence of NCDs should be a priority, and nutritional interventions are pivotal to accomplish this goal. As shown in Table 1 [10] [15] [16] [19] [23], vegetarian eating patterns promote various features associated with reducing cardiovascular disease prevalence. The Nurses' Health Study found that replacing one standard serving of red meat (3 ounces) with a vegetable protein reduced coronary heart disease (CHD) by $13 \%-30 \%[24]$.

Table 1. Comparison between vegetarian and omnivore eating patterns.

\begin{tabular}{ccc}
\hline Features & Vegetarian eating patterns & Omnivore eating patterns \\
\hline Calories & $\downarrow$ & $\uparrow$ \\
Siber & $\downarrow$ & $\uparrow$
\end{tabular}

Arrow pointing up indicates an increase; arrow pointing down indicates decrease. 


\section{Cardiovascular Disease}

According to the WHO, cardiovascular diseases (CVDs) are the leading cause of death around the world. In 2016, 17.9 million people died from CVDs, representing $31 \%$ of worldwide deaths. It is widely known that CVDs can be prevented by healthy eating patterns and increasing physical activity [25]. A systematic review and meta-analysis demonstrated a $22 \%$ and $28 \%$ decrease in CHD mortality and incidence, respectively, with a vegetarian pattern. This meta-analysis evidenced that vegetarian diets are associated with significantly lower coronary heart disease mortality (RR 0.78, 95\% CI; p < 0.0001) [26]. Also, Bechthold and colleagues demonstrated that the consumption of 2 servings/d of red meat $(170 \mathrm{~g}), 2$ servings/d of processed meat $(60 \mathrm{~g})$, and 2 servings/d of sugar-sweetened beverages $(500 \mathrm{ml})$ are associated with a $60 \%$ increase of stroke, and their omission could reduce its risk by $38 \%$ [27].

The exact reason why vegetarian patterns are protective against CVDs is not completely understood. Still, plant-based diets are characterized by having a lower saturated fat content compared to omnivore diets [6]. Trans fatty acids, found in meat and produced by chemical or enzymatic reactions, are associated with increases in triglycerides, apolipoprotein B, and LDL cholesterol [28]. Observational studies have provided evidence for a plant-based diet's benefits to achieve and maintain a healthy lipid profile [24]. Vegetarian patterns have a higher consumption of foods that lowers cholesterol and LDL-cholesterol, such as nuts, legumes, and soybean [6]. A study published in 2018 with 118 participants that lasted six months demonstrated that omnivores assigned to follow a vegetarian diet $(n=60)$ have significantly lower metabolic markers compared to participants assigned to the Mediterranean diet. The difference for LDL cholesterol was of $9.10 \mathrm{mg} / \mathrm{dL}(\mathrm{p}=0.01)$, and $12.70 \mathrm{mg} / \mathrm{dL}$ of triglycerides $(\mathrm{p}<0.01)$. The authors argued that vegetarian diets are low in cholesterol and saturated fat, leading to reduced cholesterol absorption in the bloodstream [29].

\section{Type II Diabetes}

Diabetes has reached epidemic levels, with an estimated global prevalence of 9.3\% (463 million people), documented in 2019. It is estimated that prevalence will increase to $10.9 \%$ (700 million) by 2045 [30] [31] [32]. The main causes of T2DM are modifiable and dietary interventions are one of the main pillars for prevention and treatment [31].

The Tzu Chi Health Study (TCHS), a prospective cohort study with 4625 volunteers, found that those who converted from nonvegetarian to vegetarian had $53 \%$ lower hazards (HR: 0.47, 95\% CI: 0.30, 0.71) for diabetes. This same study showed that consistent vegetarians had 35\% lower hazards (HR: 0.65, 95\% CI: $0.46,0.92)$ compared to nonvegetarians [33]. Similarly, participants from the EPIC-Oxford study were classified as regular meat-eaters (consumption of meat $>50 \mathrm{~g} / \mathrm{d}$ ), low meat-eaters ( $<50 \mathrm{~g} / \mathrm{d}$ of meat), fish-eaters, and vegetarians. The results demonstrated that regular low meat-eaters, fish-eaters and vegeta- 
rians were less likely to develop diabetes compared to meat-eaters [low meat-eaters $(\mathrm{HR}=0.63,95 \% \mathrm{CI})$, fish-eaters $(\mathrm{HR}=0.47,95 \% \mathrm{CI})$, and vegetarians $(\mathrm{HR}=0.63,95 \% \mathrm{CI})][34]$.

Seventh-Day Adventists have drawn the attention of many researchers due to their low NDCs rates. This population has only $45 \%$ the rate of diabetes of the general population. A study with 801 adult Seventh-Day Adventists found that those who consumed meat once a week had a $29 \%$ higher risk of diabetes. When the meat was processed, the risk increased to $38 \%$. The population who had a lifelong adherence to a vegetarian diet had a $74 \%$ reduced risk of developing diabetes compared to those who consumed meat weekly [31] [35].

\section{Chronic Kidney Disease}

Chronic kidney disease (CKD) is yet another public health issue due to its contribution to morbidity and mortality from NCDs [36] [37]. In 2017, the number of individuals with all stage CKD was almost 700 million, higher than those with diabetes. In the same year, CKD took 1.2 million lives, a number that has been projected to increase to 2.2 million by 2040 , in a best-case scenario [36].

$\mathrm{CKD}$ is also associated with other complications such as cardiovascular disease, uremic cardiomyopathy, vascular stiffness, and calcifications. These complications have no evidence-based treatments to effectively reverse them, once they are established [38]. Therefore, prevention is the best option. A meta-analysis that included more than 630,000 participants with normal base renal function showed that the adherence to a healthy dietary pattern was associated with $23 \%$ lower odds of developing albuminuria and $30 \%$ less incidence of CKD [39]. The Atherosclerosis Risk in Communities (ARIC) study, which is a large longitudinal observational study, including almost 12,000 adults with normal base renal function, found that there was a higher risk of incident $\mathrm{CKD}$ in individual consuming more protein from red and processed meat [Hazard Ratio 1.23 ; $\mathrm{p}<0.01]$. However no significant association between total protein consumption and incident CKD stage III [40].

A cross-sectional study that included 5316 non-diabetic participants within the Tehran lipid and glucose study framework showed that a higher intake of plant protein was directly associated with estimated glomerular filtration rate (eGFR) and a decreased risk for developing CKD. Each $20 \mathrm{~g}$ increase of plant protein was associated with a lower CKD risk (OR 0.84, 95\% CI $0.74-0.96$; $\mathrm{p}=$ 0.012). On the other hand, a higher animal protein consumption was significantly associated with a higher risk of developing CKD (OR 1.37, 95\% CI 1.05 $1.79 ; \mathrm{p}<0.05)[41]$.

\section{Animal versus Plant Protein}

Protein is the major functional and structural component of all cells of the body. They serve many functions such as kinetic, catalytic, structural, and signaling [24] [42]. It is a common concern whether vegetarian diets provide sufficient dietary protein due to animal flesh exclusion. The EPIC-Oxford cohort showed 
that protein intake in the vegetarians and vegans met the Recommended Dietary Allowance (RDA) of $0.8 \mathrm{~g} / \mathrm{kg}$ body weight. Vegetarians had a mean protein intake of $1.04 \mathrm{~g} / \mathrm{kg}$ body weight and vegans $0.99 \mathrm{~g} / \mathrm{kg}$ body weight [42] [43]. Therefore, both vegetarian and vegan diets can meet protein RDA, but what about protein's quality?

The dietary quality of protein usually refers to the limiting amino acid. This is the specific amino acid in a food that is present in the lowest proportion compared to an individual dietary requirement. It is a common misconception that plant-based proteins do not contain all 20 essential amino acids, and therefore omnivore diets are preferred. When in fact, all plant foods contain all 20 dietary amino acids [44]. Some plant-based foods can have a less optimal amino acid distribution profile; for example, lysine is low in grains, and methionine and cysteine are low in legumes [7]. Therefore, complementing plant-based proteins within the same 24 hour period can assure an adequate amino acid intake [44] [45].

Protein sources should also be considered for their interaction with microbiota. Nutrients can directly interact with microorganisms. It is well known that an animal-based diet promotes the abundance of bile-tolerant bacteria (Alstipes, Biophila, and Bacteroides) and depletion in Firmicutes that metabolize plant polysaccharides (Roseburia, Eubacterium rectale and, Ruminococcus bromii) [46]. Animal products such as red meats, processed meats and eggs are rich in choline and L-carnitine [47] [48], which can be metabolized by gut microbiota to trimethylamine (TMA), then TMA is transported by the portal circulation to the liver and converted into trimethylamine $\mathrm{N}$-oxide (TMAO). TMAO has been associated with atherosclerosis, platelet hyper-reactivity, thrombosis, and all-cause mortality in patients with health failure [48] [49].

\section{Micronutrients in Vegetarian Diets}

Micronutrient deficiencies are one of the main concerns with vegetarian diets, iron being one of them. Vegetarian and vegan diets meet iron intake recommendations due to the high consumption of food rich in iron, such as legumes, beans, and green leaves. Controversially, some studies have shown that people who follow a vegetarian diet have a higher iron than an omnivore diet. However, both vegetarians and vegans have lower ferritin levels, a biomarker used to evaluate iron deposits [50] [51]. These lower ferritin levels could be advantageous because high ferritin levels have been associated with metabolic syndrome and negative health outcomes. Multiple factors can impair iron bioavailability, such as phytic acid and polyphenols. However, ascorbic acid increases the bioavailability of non-heme iron [51] [52]. Therefore, incorporating ascorbic acid, lactic acid, malic acid, tartaric acid, carotenes, and retinol alongside iron-rich foods can increase non-heme iron absorption and prevent deficiency [50].

Cobalamin, commonly known as vitamin B12, is a water-soluble vitamin found mainly in animal protein. Therefore, people who follow a vegetarian diet are at risk of vitamin B12 deficiency. It is estimated that B12 deficiency in vege- 
tarians can vary from $0 \%$ to $86.5 \%$ in adults and the elderly [52] [53]. Vitamin B12 deficiency can lead to megaloblastic anemia, fatigue, poor cognition, and subclinical deficiency results in increased homocysteine levels. Increased homocysteine levels have been associated with an augmented risk of developing cardiovascular disease [52] [53]. The Italian Society of Human Nutrition states that fortified foods and supplementation are the only reliable source of vitamin B12 for vegans [50]. Some plant-based sources are found in fermented foods, spirulina, and nutritional yeast [52]. The Dietary Reference Intake for Cobalamin is $2.4 \mu \mathrm{g} /$ day, and supplementation in vegetarian diets is highly recommended [53]. A 12-week randomized controlled trial evaluated a low dose (350 $\mu \mathrm{g} / \mathrm{week})$ compared to a higher dose (2000 $\mu \mathrm{g} /$ week) of sublingual cyanocobalamin supplementation in 40 vegan or vegetarian subjects. The study showed that the two supplements restored serum levels of vitamin B12 and improved biomarkers in those who were deficient [54]. Therefore, there are many solutions to this concern.

Other micronutrient deficiencies may occur following a plant-based diet due to low bioavailability, antinutrients that inhibit the absorption, and the exclusion of animal sources containing different micronutrients. The population that follows a vegetarian and vegan diet usually has decreased levels of zinc, and one of the main reasons for this is due to the high content of phytic acid in this eating pattern [55]. Procedures like sprouting, milling, and soaking are recommended to increase zinc bioavailability [50]. Whenever possible, it is recommended that people who follow a vegetarian diet have periodic laboratory tests to assess possible micronutrient deficiencies, as well as a nutritional physical examination by a health professional.

\section{Conclusion}

There is substantial evidence that demonstrates the relationship between the consumption of an omnivore diet and weight gain. In contrast, vegetarian diets are associated with weight loss due to: fiber content, lower caloric density, microbiota regulation, and the release of gastrointestinal appetite-regulating hormones. The prevalence of NCDs increases along with obesity each day. However, the silver lining is that modifiable and dietary interventions are one of the main pillars for the prevention and treatment of these conditions. Plant-based eating patterns have been demonstrated to be an overall healthier diet as evidenced by having a higher Alternate Healthy Eating Index. They provide sufficient protein quality and quantity, and micronutrient deficiency can be prevented with adequate guidance by health professionals. All of the evidence presented above indicates that vegetarianism is, in fact, a potential solution for obesity and the development of non-communicable diseases.

\section{Conflicts of Interest}

The authors declare no conflicts of interest regarding the publication of this paper. 


\section{References}

[1] Ritchie, H. and Roser, M. (2020) Obesity-Our World in Data. https://ourworldindata.org/obesity

[2] WHO (2020) Obesity and Overweight. https://www.who.int/news-room/fact-sheets/detail/obesity-and-overweight

[3] Popkin, B.M., Corvalan, C. and Grummer-Strawn, L.M. (2020) Dynamics of the Double Burden of Malnutrition and the Changing Nutrition Reality. The Lancet, 395, 65-74. https://doi.org/10.1016/S0140-6736(19)32497-3

[4] WHO (2018) Noncommunicable Diseases. https://www.who.int/news-room/fact-sheets/detail/noncommunicable-diseases

[5] Huffman, S.L., Piwoz, E.G., Vosti, S.A. and Dewey, K.G. (2014) Babies, Soft Drinks and Snacks: A Concern in Low- and Middle-Income Countries? Maternal \& Child Nutrition, 10, 562-574. https://doi.org/10.1111/mcn.12126

[6] Dinu, M., Abbate, R., Gensini, G.F., Casini, A. and Sofi, F. (2017) Vegetarian, Vegan Diets and Multiple Health Outcomes: A Systematic Review with Meta-Analysis of Observational Studies. Critical Reviews in Food Science and Nutrition, 57, 3640-3649. https://doi.org/10.1080/10408398.2016.1138447

[7] Mariotti, F. and Gardner, C.D. (2019) Dietary Protein and Amino Acids in Vegetarian Diets-A Review. Nutrients, 11, 2661. https://doi.org/10.3390/nu11112661

[8] Myrmel, L.S., Fauske, K.R., Fjære, E., Bernhard, A., Liisberg, U., Hasselberg, A.E., et al. (2019) The Impact of Different Animal-Derived Protein Sources on Adiposity and Glucose Homeostasis during ad Libitum Feeding and Energy Restriction in Already Obese Mice. Nutrients, 11, 1153. https://doi.org/10.3390/nu11051153

[9] Fogelholm, M., Kanerva, N. and Männistö, S. (2015) Association between Red and Processed Meat Consumption and Chronic Diseases: The Confounding Role of Other Dietary Factors. European Journal of Clinical Nutrition, 69, 1060-1065. https://doi.org/10.1038/ejen.2015.63

[10] Vergnaud, A.-C., Norat, T., Romaguera, D., Mouw, T., May, A.M., Travier, N., et al. (2010) Meat Consumption and Prospective Weight Change in Participants of the EPIC-PANACEA Study. The American Journal of Clinical Nutrition, 92, 398-407. https://doi.org/10.3945/ajen.2009.28713

[11] Chai, W., Morimoto, Y., Cooney, R.V., Franke, A.A., Shvetsov, Y.B., Le Marchand, L., et al. (2017) Dietary Red and Processed Meat Intake and Markers of Adiposity and Inflammation: The Multiethnic Cohort Study. Journal of the American College of Nutrition, 36, 378-385. https://doi.org/10.1080/07315724.2017.1318317

[12] Salter, A.M. (2018) The Effects of Meat Consumption on Global Health. Revue Scientifique et Technique, 37, 47-55. https://doi.org/10.20506/rst.37.1.2739

[13] Serra-Majem, L., Tomaino, L., Dernini, S., Berry, E.M., Lairon, D., de la Cruz, J.N., et al. (2020) Updating the Mediterranean Diet Pyramid towards Sustainability: Focus on Environmental Concerns. International Journal of Environmental Research and Public Health, 17, 8758. https://doi.org/10.3390/ijerph17238758

[14] Medawar, E., Huhn, S., Villringer, A. and Veronica Witte, A. (2019) The Effects of Plant-Based Diets on the Body and the Brain: A Systematic Review. Translational Psychiatry, 9, Article No. 226. https://doi.org/10.1038/s41398-019-0552-0

[15] Najjar, R.S. and Feresin, R.G. (2019) Plant-Based Diets in the Reduction of Body Fat: Physiological Effects and Biochemical Insights. Nutrients, 11, 2712. https://doi.org/10.3390/nu11112712

[16] Huang, R.-Y., Huang, C.-C., Hu, F.B. and Chavarro, J.E. (2016) Vegetarian Diets 
and Weight Reduction: A Meta-Analysis of Randomized Controlled Trials. Journal of General Internal Medicine, 31, 109-116.

https://doi.org/10.1007/s11606-015-3390-7

[17] Gill, S.K., Rossi, M., Bajka, B. and Whelan, K. (2020) Dietary Fibre in Gastrointestinal Health and Disease. Nature Reviews Gastroenterology \& Hepatology, 18, 101-116. https://doi.org/10.1038/s41575-020-00375-4

[18] Turner-McGrievy, G., Mandes, T. and Crimarco, A. (2017) A Plant-Based Diet for Overweight and Obesity Prevention and Treatment. Journal of Geriatric Cardiology, 14, 369-374.

[19] Campbell, E.K., Fidahusain, M. and Campbell II, T.M. (2019) Evaluation of an Eight-Week Whole-Food Plant-Based Lifestyle Modification Program. Nutrients, 11, 2068. https://doi.org/10.3390/nu11092068

[20] Moore, W.J., McGrievy, M.E. and Turner-McGrievy, G.M. (2015) Dietary Adherence and Acceptability of Five Different Diets, Including Vegan and Vegetarian Diets, for Weight Loss: The New DIETs Study. Eating Behaviors, 19, 33-38. https://doi.org/10.1016/j.eatbeh.2015.06.011

[21] Thom, G. and Lean, M. (2017) Is There an Optimal Diet for Weight Management and Metabolic Health? Gastroenterology, 152, 1739-1751. https://doi.org/10.1053/j.gastro.2017.01.056

[22] American Diabetes Association (ADA) (2014) Dietetics A of N and Choose Your Foods, Food Lists for Weight Management. USA, 1-64.

[23] Klementova, M., Thieme, L., Haluzik, M., Pavlovicova, R., Hill, M., Pelikanova, T., et al. (2019) A Plant-Based Meal Increases Gastrointestinal Hormones and Satiety More than an Energy- and Macronutrient-Matched Processed-Meat Meal in T2D, Obese, and Healthy Men: A Three-Group Randomized Crossover Study. Nutrients, 11, 1-10. https://doi.org/10.3390/nu11010157

[24] Zhubi-Bakija, F., Bajraktari, G., Bytyçi, I., Mikhailidis, D.P., Henein, M.Y., Latkovskis, G., et al. (2021) The Impact of Type of Dietary Protein, Animal versus Vegetable, in Modifying Cardiometabolic Risk Factors: A Position Paper from the International Lipid Expert Panel (ILEP). Clinical Nutrition, 40, 255-276.

https://doi.org/10.1016/j.clnu.2020.05.017

[25] WHO (2017) Cardiovascular Diseases. WHO, Geneva.

[26] Glenn, A.J., Viguiliouk, E., Seider, M., Boucher, B.A., Khan, T.A., Blanco Mejia, S., et al. (2019) Relation of Vegetarian Dietary Patterns with Major Cardiovascular Outcomes: A Systematic Review and Meta-Analysis of Prospective Cohort Studies. Frontiers in Nutrition, 6. https://doi.org/10.3389/fnut.2019.00080

[27] Bechthold, A., Boeing, H., Schwedhelm, C., Hoffmann, G., Knüppel, S., Iqbal, K., et al. (2019) Food Groups and Risk of Coronary Heart Disease, Stroke and Heart Failure: A Systematic Review and Dose-Response Meta-Analysis of Prospective Studies. Critical Reviews in Food Science and Nutrition, 59, 1071-1090.

https://doi.org/10.1080/10408398.2017.1392288

[28] Sacks, F.M., Lichtenstein, A.H., Wu, J.H.Y., Appel, L.J., Creager, M.A., Kris-Etherton, P.M., et al. (2017) Dietary Fats and Cardiovascular Disease: A Presidential Advisory from the American Heart Association. Circulation, 136, e1-e23. https://doi.org/10.1161/CIR.0000000000000510

[29] Sofi, F., Dinu, M., Pagliai, G., Cesari, F., Gori, A.M., Sereni, A., et al. (2018) Low-Calorie Vegetarian versus Mediterranean Diets for Reducing Body Weight and Improving Cardiovascular Risk Profile. Circulation, 137, 1103-1113. https://doi.org/10.1161/CIRCULATIONAHA.117.030088 
[30] Saeedi, P., Petersohn, I., Salpea, P., Bright, D. and Williams, R. (2019) Global and Regional Diabetes Prevalence Estimates for 2019 and Projections for 2030 and 2045: Results from the International Diabetes Federation Diabetes Atlas, 9th Edition. Diabetes Research and Clinical Practice, 157, Article ID: 107843. https://doi.org/10.1016/j.diabres.2019.107843

[31] Tonstad, S. and Clifton, P. (2017) 20-Vegetarian Diets and the Risk of Type 2 Diabetes. In: Vegetarian and Plant-Based Diets in Health and Disease Prevention, Academic Press, 355-367. https://doi.org/10.1016/B978-0-12-803968-7.00020-4

[32] Cho, N.H., Shaw, J.E., Karuranga, S., Huang, Y., da Rocha Fernandes, J.D., Ohlrogge, A.W., et al. (2018) IDF Diabetes Atlas: Global Estimates of Diabetes Prevalence for 2017 and Projections for 2045. Diabetes Research and Clinical Practice, 138, 271-281. https://doi.org/10.1016/j.diabres.2018.02.023

[33] Chiu, T.H.T., Pan, W.H., Lin, M.N. and Lin, C.L. (2018) Vegetarian Diet, Change in Dietary Patterns, and Diabetes Risk: A Prospective Study. Nutrition \& Diabetes, 8, Article No. 12. https://doi.org/10.1038/s41387-018-0022-4

[34] Papier, K., Appleby, P.N., Fensom, G.K., Knuppel, A., Perez-Cornago, A., Schmidt, J.A., et al. (2019) Vegetarian Diets and Risk of Hospitalisation or Death with Diabetes in British Adults: Results from the EPIC-Oxford Study. Nutrition \& Diabetes, 9, Article No. 7. https://doi.org/10.1038/s41387-019-0074-0

[35] Vang, A., Singh, P.N., Lee, J.W., Haddad, E.H. and Brinegar, C.H. (2008) Meats, Processed Meats, Obesity, Weight Gain and Occurrence of Diabetes among Adults: Findings from Adventist Health Studies. Annals of Nutrition and Metabolism, 52, 96-104. https://doi.org/10.1159/000121365

[36] Bikbov, B., Purcell, C.A., Levey, A.S., Smith, M., Abdoli, A., Abebe, M., et al. (2020) Global, Regional, and National Burden of Chronic Kidney Disease, 1990-2017: A Systematic Analysis for the Global Burden of Disease Study 2017. The Lancet, 395, 709-733. https://doi.org/10.1016/S0140-6736(20)30045-3

[37] Watanabe, S. (2017) Low-Protein Diet for the Prevention of Renal Failure. Proceedings of the Japan Academy, Series B, 93, 1-9. https://doi.org/10.2183/pjab.93.001

[38] Lees, J.S. and Mark, P.B. (2020) Fruit for Thought: Lifestyle Interventions to Reduce the Risk of Future Chronic Kidney Disease. Nephrology Dialysis Transplantation, gfaa266, 1-3. https://doi.org/10.1093/ndt/gfaa266

[39] Bach, K.E., Kelly, J.T., Campbell, K.L., Palmer, S.C., Khalesi, S. and Strippoli, G.F.M. (2019) Healthy Dietary Patterns and Incidence of CKD: A Meta-Analysis of Cohort Studies. Clinical Journal of the American Society of Nephrology, 14, 1441-1449. https://doi.org/10.2215/CJN.00530119

[40] Chauveau, P., Koppe, L., Combe, C., Lasseur, C., Trolonge, S. and Aparicio, M. (2019) Vegetarian Diets and Chronic Kidney Disease. Nephrology Dialysis Transplantation, 34, 199-207. https://doi.org/10.1093/ndt/gfy164

[41] Yuzbashian, E., Asghari, G., Mirmiran, P., Hosseini, F.S. and Azizi, F. (2015) Associations of Dietary Macronutrients with Glomerular Filtration Rate and Kidney Dysfunction: Tehran Lipid and Glucose Study. Journal of Nephrology, 28, 173-180. https://doi.org/10.1007/s40620-014-0095-7

[42] Institute of Medicine (2005) Dietary Reference Intakes for Energy, Carbohydrate, Fiber, Fat, Fatty Acids, Cholesterol, Protein, and Amino Acids (Macronutrients). Dietary Reference Intakes for Energy, Carbohydrate, Fiber, Fat, Fatty Acids, Cholesterol, Protein, and Amino Acids (Macronutrients). 1-1331.

[43] Sobiecki, J.G., Appleby, P.N., Bradbury, K.E. and Key, T.J. (2016) High Compliance 
with Dietary Recommendations in a Cohort of Meat Eaters, Fish Eaters, Vegetarians, and Vegans: Results from the European Prospective Investigation into Cancer and Nutrition-Oxford Study. Nutrition Research, 36, 464-477.

https://doi.org/10.1016/j.nutres.2015.12.016

[44] Gardner, C.D., Hartle, J.C., Garrett, R.D., Offringa, L.C. and Wasserman, A.S. (2019) Maximizing the Intersection of Human Health and the Health of the Environment with Regard to the Amount and Type of Protein Produced and Consumed in the United States. Nutrition Reviews, 77, 197-215. https://doi.org/10.1093/nutrit/nuy073

[45] Young, V.R. and Pellett, P.L. (2018) Plant Proteins in Relation to Human and Amino Acid Nutrition. The American Journal of Clinical Nutrition, 59, 1203S-1212S. https://doi.org/10.1093/ajcn/59.5.1203S

[46] David, L.A., Maurice, C.F., Carmody, R.N., Gootenberg, D.B., Button, J.E., Wolfe, B.E., et al. (2014) Diet Rapidly and Reproducibly Alters the Human Gut Microbiome. Nature, 505, 559-563. https://doi.org/10.1038/nature12820

[47] Shen, T.-C.D. (2017) Diet and Gut Microbiota in Health and Disease. Nestle Nutrition Institute Workshop Series, 88, 117-126. https://doi.org/10.1159/000455220

[48] Koeth, R.A., Wang, Z., Levison, B.S., Buffa, J.A., Org, E., Sheehy, B.T., et al. (2013) Intestinal Microbiota Metabolism of L-Carnitine, a Nutrient in Red Meat, Promotes Atherosclerosis. Nature Medicine, 19, 576-585. https://doi.org/10.1038/nm.3145

[49] Liu, T.X., Niu, H.T. and Zhang, S.Y. (2015) Intestinal Microbiota Metabolism and Atherosclerosis. Chinese Medical Journal (EngI), 128, 2805-2811.

https://doi.org/10.4103/0366-6999.167362

[50] Agnoli, C., Baroni, L., Bertini, I., Ciappellano, S., Fabbri, A., Papa, M., et al. (2017) Position Paper on Vegetarian Diets from the Working Group of the Italian Society of Human Nutrition. Nutrition, Metabolism and Cardiovascular Diseases, 27, 1037-1052. https://doi.org/10.1016/j.numecd.2017.10.020

[51] Haider, L.M., Schwingshackl, L., Hoffmann, G. and Ekmekcioglu, C. (2018) The Effect of Vegetarian Diets on Iron Status in Adults: A Systematic Review and Meta-Analysis. Critical Reviews in Food Science and Nutrition, 58, 1359-1374. https://doi.org/10.1080/10408398.2016.1259210

[52] Melina, V., Craig, W. and Levin, S. (2016) Position of the Academy of Nutrition and Dietetics: Vegetarian Diets. Journal of the Academy of Nutrition and Dietetics, 116, 1970-1980. https://doi.org/10.1016/j.jand.2016.09.025

[53] Rizzo, G., Laganà, A.S., Rapisarda, A.M.C., La Ferrera, G.M.G., Buscema, M., Rossetti, P., et al. (2016) Vitamin B12 among Vegetarians: Status, Assessment and Supplementation. Nutrients, 8, 767. https://doi.org/10.3390/nu8120767

[54] Del Bo, C., Riso, P., Gardana, C., Brusamolino, A., Battezzati, A. and Ciappellano, S. (2019) Effect of Two Different Sublingual Dosages of Vitamin B 12 on Cobalamin Nutritional Status in Vegans and Vegetarians with a Marginal Deficiency: A Randomized Controlled Trial. Clinical Nutrition, 38, 575-583. https://doi.org/10.1016/j.clnu.2018.02.008

[55] Foster, M., Chu, A., Petocz, P. and Samman, S. (2013) Effect of Vegetarian Diets on Zinc Status: A Systematic Review and Meta-Analysis of Studies in Humans. Journal of the Science of Food and Agriculture, 93, 2362-2371. https://doi.org/10.1002/jsfa.6179 